\title{
Ocular Adnexal Lymphoma cM1b TNM
}

\section{Finding v8}

National Cancer Institute

\section{Source}

National Cancer Institute. Ocular Adnexal Lymphoma cM1b TNM Finding v8. NCI

Thesaurus. Code C140856.

Ocular adnexal lymphoma with lymphomatous involvement of the bone marrow. (from AJCC 8th Ed.) 